\title{
CLEANING OF ULTRAFILTRATION MEMBRANES AFTER TREATMENT OF SURFACE WATER: STATIC-DYNAMIC TEST
}

\author{
B. García-Fayos ${ }^{1}$, M. Sancho ${ }^{1}$, J.M. Arnal ${ }^{1}$ \\ ${ }^{1}$ Chemical and Nuclear Engineering Department. Universitat Politècnica de València. Camino de Vera s/n \\ 46022 Valencia, Spain. Tel. +34 (96) 3879633; Fax +34 (96) 3877639, email: jarnala@iqn.upv.es, \\ beagarfa@iqn.upv.es, msanchof@iqn.upv.es
}

\begin{abstract}
Access to safe drinkable water is a basic human right and an international development goal. AQUAPOT international project, created by Chemical and Nuclear Engineering Department of the Polytechnic University of Valencia, has been focused on research and development of low-cost and effective water treatment technologies based on membrane technology able to be used in developing countries. After several years of intensive laboratory and field research, Aquapot's UF plants have been settled in different locations of Ecuador (province of Azuay) and Mozambique (province of Maputo).

At present, most of the installed plants work successfully, producing drinking water suitable for human consumption and even for industrial use. However, installation of the designed UF-drinking water treatment facilities has shown that cleaning standard protocol of ultrafiltration membranes is not effective. This fact could affect microbiological quality and volume of the pure water produced and also life of the membrane and the UF-plant.

In order to develop optimized cleaning protocols based on the use of common and accessible chemicals, Aquapot started an applied research studying several cleaning methods. Previous studies have been focussed in applying different types of cleaning: chemical cleaning (by means of static tests and dynamic tests) and physico-chemical cleaning (combining chemical reagents with the hydrodynamic action of air bubbles).

This work describes the experimental procedure performed in static-dynamic cleaning test which combine soaking with dynamic circulation of cleaning solutions. Sodium hypochlorite and Hydrogen Peroxide at $25{ }^{\circ} \mathrm{C}$ performed the best results, recovering permeate flux from 10 to 12 times respectively compared with fouled membranes. Main results obtained for the different chemical solutions tested at 25 and $40{ }^{\circ} \mathrm{C}$ were also compared with previous chemical (static and dynamic test) and physico-chemical cleanning. Results showed that the tested cleaning protocol improves the effectiveness of the cleaning and recovers UF membrane performance even until 30 times, when sequence of cleaning is Sodium hypochlorite followed by hydrogen peroxide.
\end{abstract}

Keywords: UF, membrane cleaning, AQUAPOT, static-dynamic test, drinking water 


\section{Introduction}

In recent years, application of pressure-driven membrane processes as ultrafiltration (UF) have expanded as an alternative promising technology to obtain drinking water for human consumption [1]. Despite the strong potential of membranes, one of the common problems encountered in applications is membrane fouling.

Fouling is a process resulting in loss of performance of a membrane due to deposition of suspended or dissolved substances on its external surface, at its pore openings or within its pores [2]. Inorganics, biological foulants, suspended solids, colloids, metal oxides, and organics are main species in the feed that contribute fouling of membrane [3]. The main consequences of fouling are: flux decline, permeate quality deterioration and energy consumption increase.

The main mechanisms of membrane fouling are the following [4]:

- Adsorption, due to chemical affinity or interaction between solutes and membrane material. This can happen at membrane surface or inside the pores.

- Pore blockage, when solutes go inside membrane pores.

- Gel formation, as a consequence of molecule accumulation at the film layer of the membrane. This is very typical in solutions containing proteins.

- Biofouling, cause by bacterial adhesion and growth at membrane surface, besides the production of extracellular polysaccharides (EPS) by some genera of bacteria, which in fact are the substance responsible for the biofilm (Baker \& Dudley, 1998).

There are many factors contributing to fouling including surface properties (chemistry, morphology, etc.), hydrodynamic conditions, ionic strength and solute concentration [5].

Until now, main research has been focussed on the study of flux decline behaviour, understanding of fouling mechanisms, prediction of fouling as well as the characterization of fouling agents. These tools have been considered primordial to understand fouling phenomenon and its prevention, developing modified membrane materials [6] and better pretreatments [7]. Studies about cleaning, specially in UF and MF have been considered secondary, even it is critical to plant operation [8].

\subsection{Membrane cleaning}

Membrane cleaning is an essential step in maintaining the permeability and selectivity of a membrane process. Cleaning can be defined as a process where material is relieved of a substance which is not an integral part of the membrane material [9]. Nowadays, cleaning techniques for membranes restoration could be broadly categorized into four types: physical, chemical, physico-chemical and biochemical methods, even the three first are the most common.

\subsubsection{Physical cleaning}

Physical cleaning methods use mechanical forces to dislodge and remove foulants from the membrane surface. Physical methods include sponge ball cleaning, hydraulic cleaning (forward, reverse flushing and backwashing), air flushing (also called air 
sparging, air scouring or air bubbling), vibration, and $\mathrm{CO}_{2}$ back permeation [10-11]. Non-conventional physical cleaning methods are the application of ultrasonic [12-14], electrical fields [15] and magnetic fields [16-17] with different results. Hydraulic cleaning methods are often adopted in UF for drinking water treatment [18].

\subsubsection{Chemical cleaning}

Chemical cleaning is the most common membrane cleaning method, especially in UF membranes. In this type of cleaning, the choice of the cleaning agent is critical. The optimal selection of the cleaning agent depends mainly on membrane material and type of foulant.

Chemical cleaning depends purely on chemical interactions to remove foulants from membrane surface. Chemical reactions involved in cleaning include hydrolysis, peptization, saponification, solubilization, dispersion and chelation [19]. There are five categories of chemical cleaning agents: alkaline solutions, acids, acid or alkaline metal chelating agents, surfactants, and enzymes [8]. Chemical agents react with deposits, scales, corrosion products, and other foulants. The chemical should loose and dissolve the foulants, keep the foulant in dispersion, avoid new fouling, as well as maintain membrane properties [20].

A cleaning cycle generally includes several stages: product removal, rinsing with water, cleaning in one or more steps, and rinsing with water. In order to obtain a good cleaning effect, cross-flow velocity should be higher and the pressure lower than those used during normal operation [21].

Other important aspects concerning chemical cleaning are temperature, chemical concentration, $\mathrm{pH}$, pressure and flow, and time [22-19]. Some studies suggest that there is an optimal temperature for chemical cleaning [23]. Usually, increasing temperature (always below recommended membrane maximum temperature) increases cleaning efficiency, cross-flow velocity seems to have no effect on cleaning results, whereas increasing trans-membrane pressure may even decrease cleaning efficiency. Zero transmembrane pressure is recommended for maximum efficiency in deposit removal [23]. With regard to the time required for cleaning it varies according to the foulant and the cleaning process.

\subsubsection{Physico-chemical cleaning methods}

The physico-chemical cleaning methods use physical cleaning methods with the addition of chemical agents to enhance cleaning effectiveness. Very few works have researched on simultaneous combination of physical and chemical methods for membrane cleaning by using air bubbles between modes of filtration [24-26].

Actually, not also cleaning is important to prevent fouling, several operating parameters on fouling including flux, concentrate velocity, backwash frequency, and transmembrane pressure have to be chosen depending on the water quality to insure a long term operations of the membrane. 


\subsection{Cleaning strategies under the scope of the Aquapot project}

Membrane systems are attractive to obtain drinking water since they provide an absolute barrier for pathogens and remove turbidity, thus increasing the palatability of the water. The costs of membrane have decreased rapidly during the last decades and therefore membrane systems have also become within reach for application in low-cost applications [27].

Lack of chemical cleaning agents, its high cost or application of not optimized cleaning protocols are the main reasons that explain permeate flux decline and main disadvantages that limits the feasibility of this technology in water treatment processes, specially in rural areas of developing countries [28].

Aware that the fouling and cleaning are even more critical in remote areas, the Aquapot project has been investigating since 2004 cleaning strategies for recovering permeate flow in spiral-wound UF membranes installed in rural areas of Ecuador and Mozambique [29-31]. FTIR, SEM and EDX analysis done to the UF membrane proved that the membrane surface was covered with a compact gel layer formed by organic substances and inorganic elements such as $\mathrm{Mg}, \mathrm{Al}, \mathrm{Ca}, \mathrm{Si}$ or $\mathrm{Fe}$ coming from the surface water that caused irreversible fouling [32].

Cleaning research strategy was defined considering physical, chemical (static and dynamic test) and physico-chemical techniques including the study of the influence of temperature, chemical concentration, $\mathrm{pH}$, pressure, flow and time over membrane cleaning [22]. Chemicals were chosen according to the membrane manufacturer's recommendations, bibliography consulted $[9,18,33]$ and also considering its affordability, low cost and world-wide extension.

In static test [33], best chemicals were sodium hypochlorite $\left(25^{\circ} \mathrm{C}\right)$, hydrogen peroxide $\left(25^{\circ} \mathrm{C}\right.$ ) and a commercial solution called Auxiclean B.13 at $40^{\circ} \mathrm{C}$ (alkaline solution with complexing agents) from Auxicolor S.A. Evaluation of this effectivity was done through cualitative methods.

Dynamic test [32] performed after static test, revealed that best cleaning solutions were Sodium hypochlorite at $25^{\circ} \mathrm{C}$, Hydrogen Peroxide at 25 and $40{ }^{\circ} \mathrm{C}$ and Auxiclean B. 13 at 25 and $40^{\circ} \mathrm{C}$ after 2 hour cleaning.

Physico-chemical dynamic test [24] performed studied the cleaning of UF membranes by the application of air in combination with different chemical solutions, with the objective of testing both hydraulic and chemical actions simultaneously in spiral wound membranes. The experimental results were compared to those obtained with chemical solutions without air bubbles, and showed a significant improvement in the cleaning effectiveness when using air bubbles with chemical solutions, also when comparing the results with the ones obtained with air sparging without chemical agents.

The present paper studies the effect of cleaning strategies in flux recovery performing static-dynamic tests over a previously fouled UF membrane and its comparison with the previously tested cleaning conditions. Chemicals used in these tests, are those which obtained the best partial results in static [33], dynamic [32] and physico-chemical dynamic [24] test. 


\section{Materials and Methods}

\subsection{Feed water characteristics and pilot plant}

Feed water characteristics and fouling characterization were described in previous studies [25, 31-33] as well as the pilot plant used.

\subsection{Cleaning procedure in static-dynamic tests}

\section{1) Water permeability before cleaning}

Membranes were tested to determine the initial water permeability with deionised water at a transmembrane pressure of 0.2 MPa. All the samples were taken from the same spiral wound UF module, from different positions in the module representing the whole membrane area. Four membrane samples were tested at the same time. Permeate flow of each sample was measured every 15 minutes during 1 hour. Each experiment was done three times. Average permeate flux was then calculated for each membrane and defined as $\mathrm{J}_{0}\left(\mathrm{~L} / \mathrm{m}^{2} \cdot \mathrm{h}\right)$. Water permeability was done at $25^{\circ} \mathrm{C}$ or $40{ }^{\circ} \mathrm{C}$ depending on the cleaning temperature used for each solution as a reference.

\section{2) Membrane cleaning with chemical solutions}

The chemicals and temperature conditions tested in the experiments (Table 1) were chosen as a consequence of the results obtained in the previous static tests [33], dynamic [32] and dynamic test using bubbles [24].

Table 1. Chemical solutions used in the cleaning experiments

\begin{tabular}{|l|l|l|l||}
\hline Solution & Concentration & $\mathrm{pH}$ & $\begin{array}{l}\text { Temperature } \\
\left({ }^{\circ} \mathrm{C}\right)\end{array}$ \\
\hline \hline “Auxiclean B.13”(*) & $2 \%(\mathrm{w} / \mathrm{v})$ & 11 & 40 \\
\hline Sodium hypochlorite $(\mathrm{NaClO})(* *)$ & $100 \mathrm{ppm}$ & 11 & $25-40$ \\
\hline Hydrogen peroxide $\left(\mathrm{H}_{2} \mathrm{O}_{2}\right)(* *)$ & $0,5 \%(\mathrm{v} / \mathrm{v})$ & 7.7 & 25 \\
\hline $\mathrm{H}_{2} \mathrm{O}$ (included as control) & --- & 5.8 & $25-40$ \\
\hline
\end{tabular}

(*) Supplier Auxicolor S.A. (**) Supplier PANREAC Spain

Cleaning time was 8 hours. Each hour, chemical solution was recycled back for 15 minutes (dynamic cleaning) at a transmembrane pressure of $0.2 \mathrm{MPa}$ and with a feed flow of $160 \mathrm{~L} / \mathrm{h}$. After this, membranes remained soaked in the chemical solution for 45 minutes (static cleaning). Due to total cleaning time is 8 hours, total dynamic cleaning time (15 minutes each hour during 8 hours) equals the time of 2 hours of dynamic cleaning used in previous dynamic test [32]. Temperature remained constant during the experiment due to a temperature control unit installed.

\section{3) Water permeability after cleaning}

After the chemical cleaning, water permeability with deionised water was again determined (named $\mathrm{J}_{1}\left(\mathrm{~L} / \mathrm{m}^{2} \cdot \mathrm{h}\right)$ ) in order to compare it with the initial value and to 
calculate the degree of flux restoration after cleaning. Conditions for the test were the same as the previously described for "Water permeability before cleaning".

The ratio of the pure water flux after chemical cleaning (J1) to the flux before chemical cleaning (J0) is used to express the degree of flux restoration (Equation 1):

$$
\text { Degree of flux restoration }=\frac{J_{1}}{J_{0}}(\text { Eq. 1) }
$$

This experimental procedure was carried out twice for each solution. Cleaning conditions shown would not cause damage on the membrane since the concentrations examined in this study were within the ranges recommended by the membrane's manufacturer. After each experiment, cleaned membranes were replaced for new fouled samples.

\subsection{Optimization of the results}

After analizing the results obtained following this methodology, the same steps were followed for the best solutions in a long-term test, increasing cleaning time from 8 to 16 hours. In the first 8 hours static-dynamic test was followed using one chemical solution, and the last 8 hours static-dynamic conditions were performed for the other chemical solution. In order to verify the influence that cleaning sequence has over degree of flux restoration, variations in cleaning sequence were also performed.

\section{Results and Discussion}

\subsection{Permeate flux analysis before and after cleaning}

Effectiveness of cleaning procedure in removing fouling and recovering membrane performance was determined by comparing permeate fluxes before and after chemical cleaning. Figures 1 and 2 show the experimental results obtained when cleaning membrane samples at $25^{\circ} \mathrm{C}$.

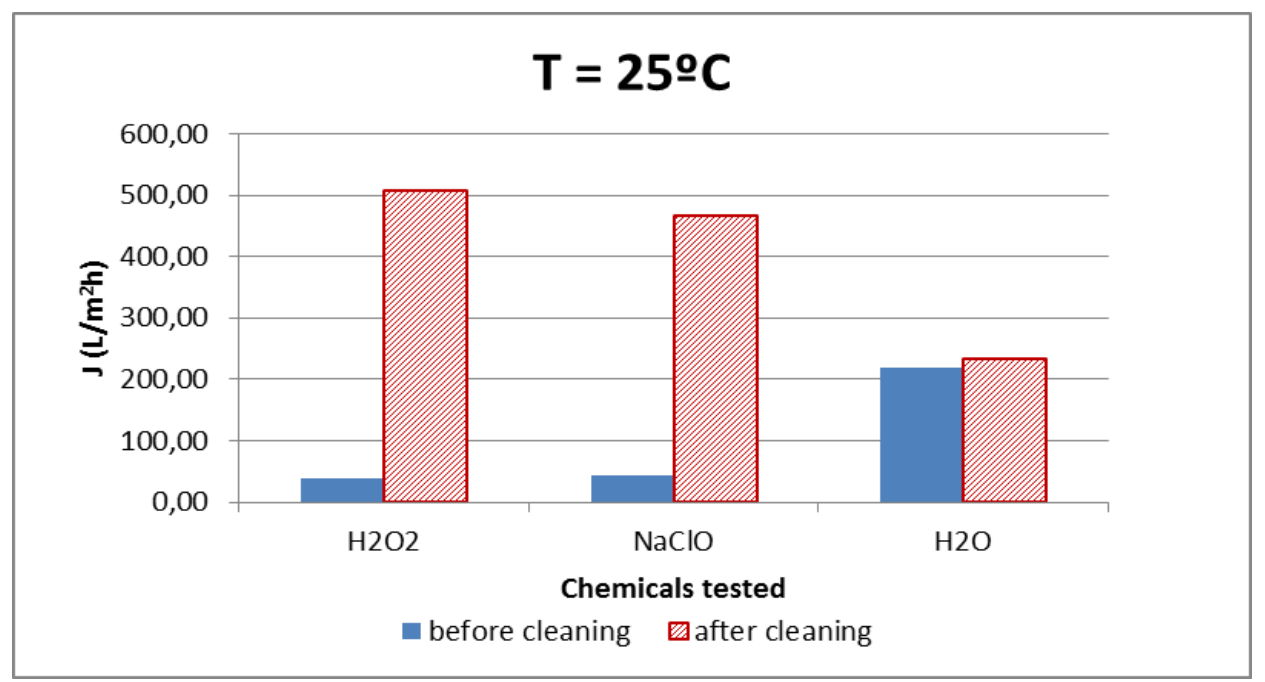

Figure 1. Flux permeate before and after cleaning under static-dynamic conditions at $25{ }^{\circ} \mathrm{C}$ 
It can be observed that the values of permeate flux during the cleaning stage were quite similar for all the tested solutions (Hydrogen Peroxide and Sodium Hypochlorite), but it seems that Hydrogen Peroxide gets better final values of flux $\left(500 \mathrm{~L} / \mathrm{m}^{2} \mathrm{~h}\right)$, while the values obtained with deionised water are the lower ones.

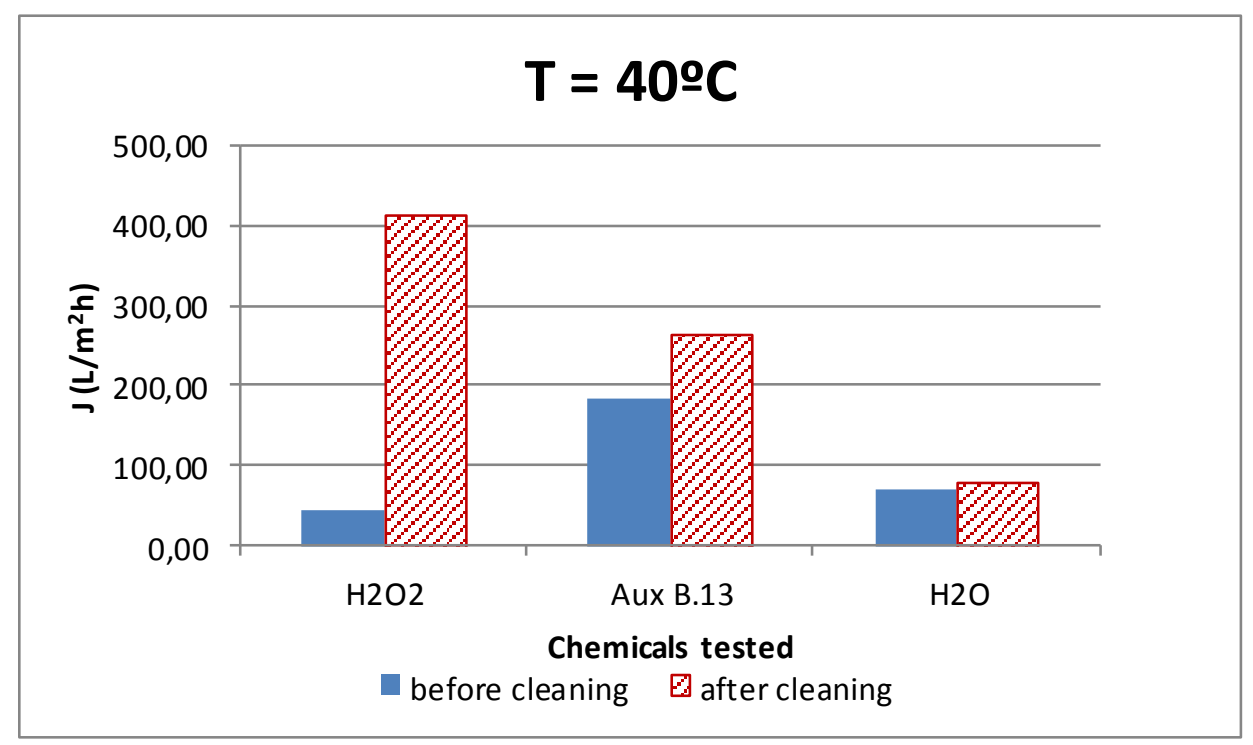

Figure 2. Flux permeate before and after cleaning under static-dynamic conditions at $40{ }^{\circ} \mathrm{C}$

At $40^{\circ} \mathrm{C}$, results obtained for Hydrogen peroxide are similar that those obtained for 25 ${ }^{\circ} \mathrm{C}$, reaching high values of flux permeate $\left(400 \mathrm{~L} / \mathrm{m}^{2} \mathrm{~h}\right)$. For commercial solution "Auxiclean B.13", the effect is not as sharp as in the case of hydrogen peroxide.

The effect of the hydrodynamic regime (static-dynamic) seems not to affect the membranes when a cleaning chemical is not used. For the case of distilled water, no improved effect for flux permeate is observed at this temperature.

\subsection{Analysis of the degree of flux recovery}

Figure 3 and 4 show the degree of flux restoration $(\mathrm{J} 1 / \mathrm{J} 0)$ of the fouled membranes in terms of pure water flux by chemical cleaning with a single reagent.

According to the results presented in Figure 3, at a temperature of $25^{\circ} \mathrm{C}$, the best chemical solution is the hydrogen peroxide which shows a degree of flux restoration above 12.9. Sodium hypochlorite shows also very good flux restoration values of 10.8 on average; while distilled water showed values of flux restoration very low, around 1.05 . 


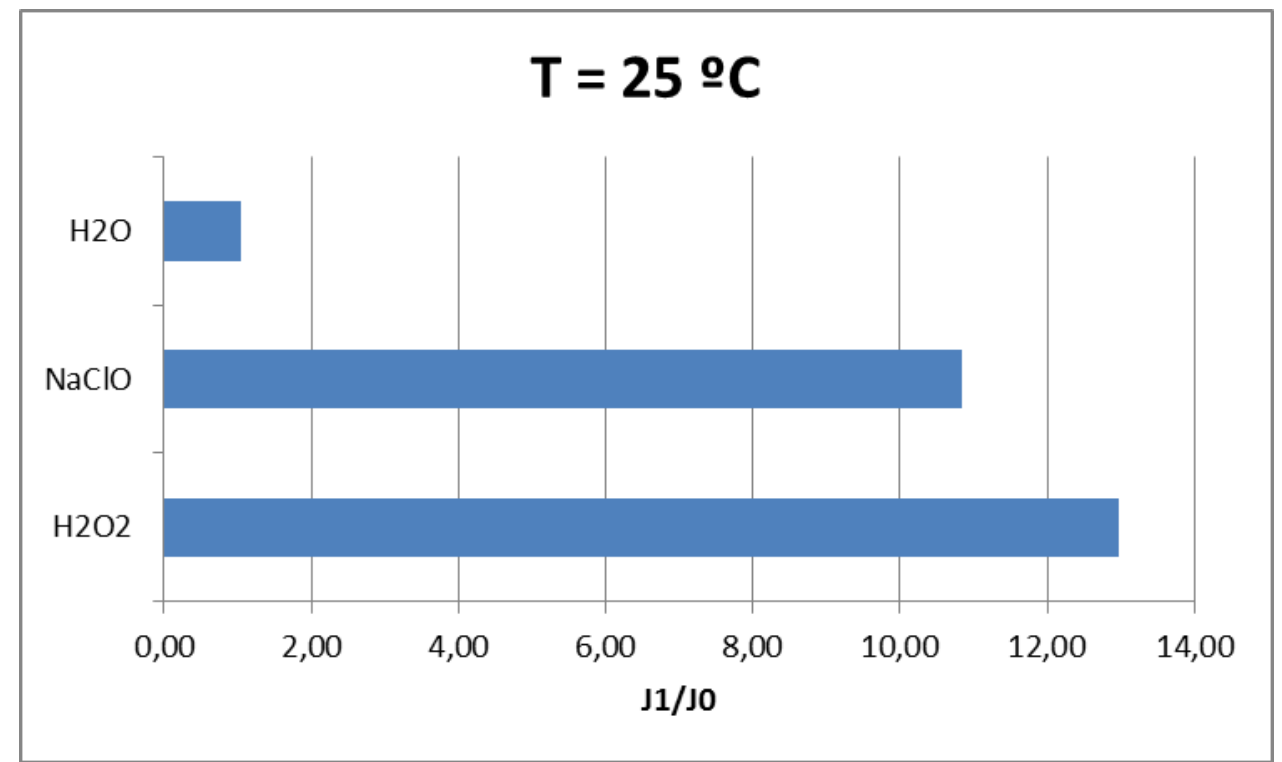

Figure 3. Degree of flux restoration in the static-dynamic tests at $25^{\circ} \mathrm{C}$

At a temperature of $40^{\circ} \mathrm{C}$, as it is shown in Figure 4, the best chemical solution was also hydrogen peroxide with a degree of flux restoration of 9.1. On the other hand, commercial solution "Auxiclean B.13" showed poor values of permeate flux recovery, with values of 1.4. Sodium hypochlorite was not tested at this temperature because only the best solutions defined in previous experiments [33] have been selected for these experiments. Lastly, distilled water did not show any permeability recovery, with values of permeate flux before cleaning very similar to those after cleaning.

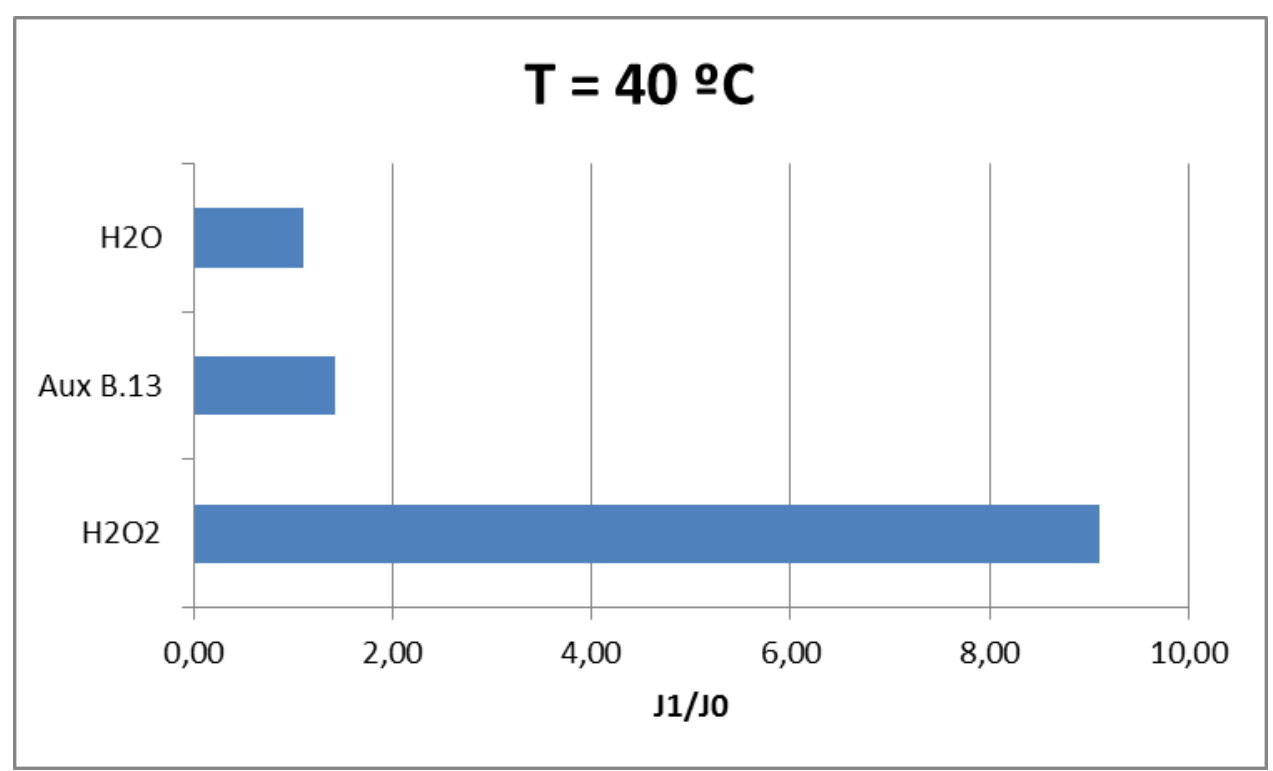

Figure 4. Degree of flux restoration in the static-dynamic tests at $40^{\circ} \mathrm{C}$

\subsection{Comparison of static-dynamic test with different cleaning methods}

In order to study the effect of static-dynamic conditions in cleaning efficiency, results of this type of cleaning are compared with the ones obtained in chemical cleaning tests (dynamic) [32] and physico-chemical cleaning test (dynamic using air bubbles)[24] performed previously. 
In Figure 5, it can be seen that for hydrogen peroxide and for sodium hypochlorite, application of static-dynamic strategies improves the degree of flux restoration. For hydrogen peroxide flux is increased 12 times compared with dynamic and dynamic test using air bubbles. For sodium hypochlorite the combination of soaking and recirculation of chemical solution increases in 10 times de degree of flux restoration compared with dynamic test and in 5 times compared with dynamic test using air bubbles. No significant effects were observed for distillated water regardless of the type of cleaning method used.

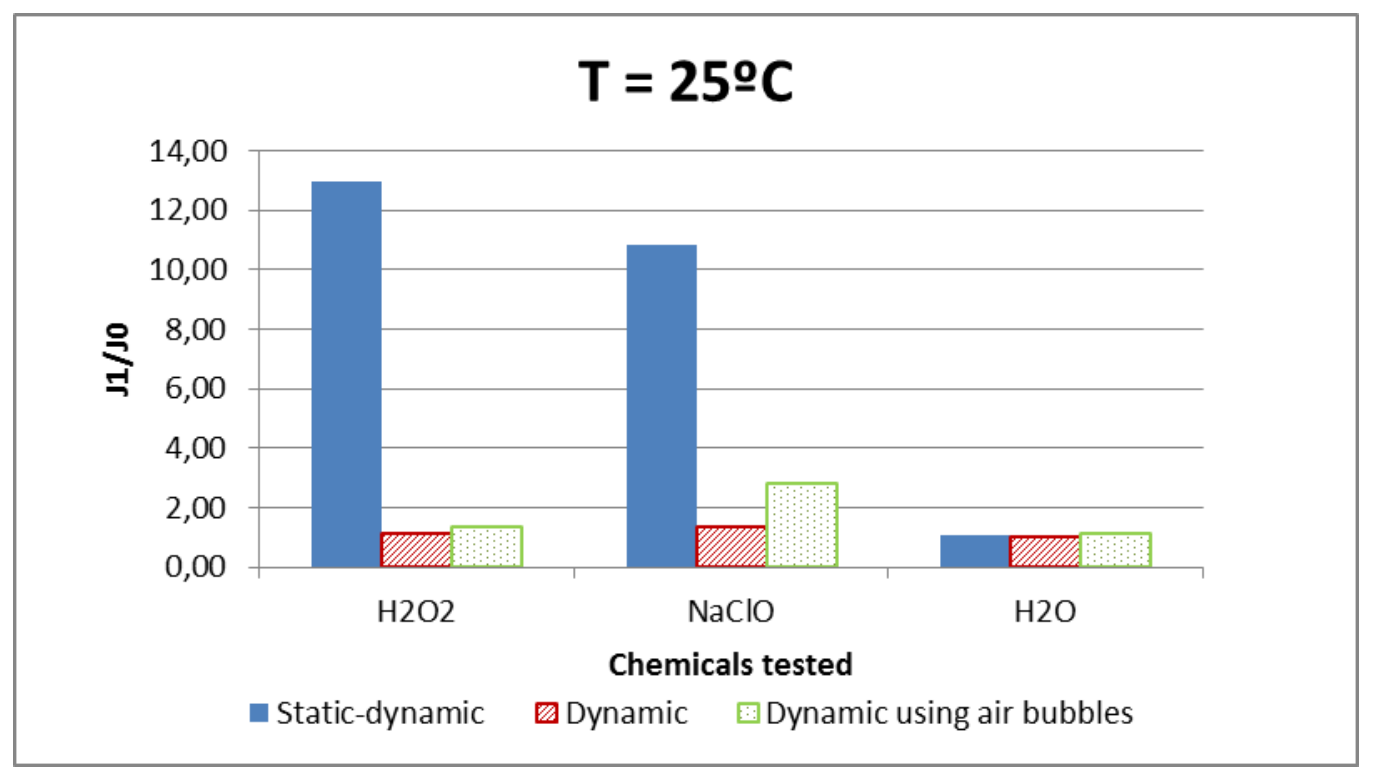

Figure 5. Effect of static-dynamic strategies in membrane cleaning at $25^{\circ} \mathrm{C}$

In Figure 6, it is shown the comparison for the best solutions used at $40{ }^{\circ} \mathrm{C}$. For hydrogen peroxide, the results are similar to those obtained at $25^{\circ} \mathrm{C}$. There is a clear benefit in the use of static-dynamic strategies, compared with dynamic and dynamic using air bubbles methodologies. Degree of flux restoration observed for hydrogen peroxide is increased 9 times compared with dynamic assays and 4.5 times compared with dynamic test using air bubbles. However, the value obtained (9.1) is lower than the one obtained at $25{ }^{\circ} \mathrm{C}(12.9)$. It seems that the increase of temperature could reduce the effectiveness of the oxidant solution. This effect is also observed for the alkaline commercial solution "Auxiclean B.13" in spite of being the temperature recommended by the manufacturer. In this case, the trial duration time can have diminished the effectiveness of the cleaning solution. 


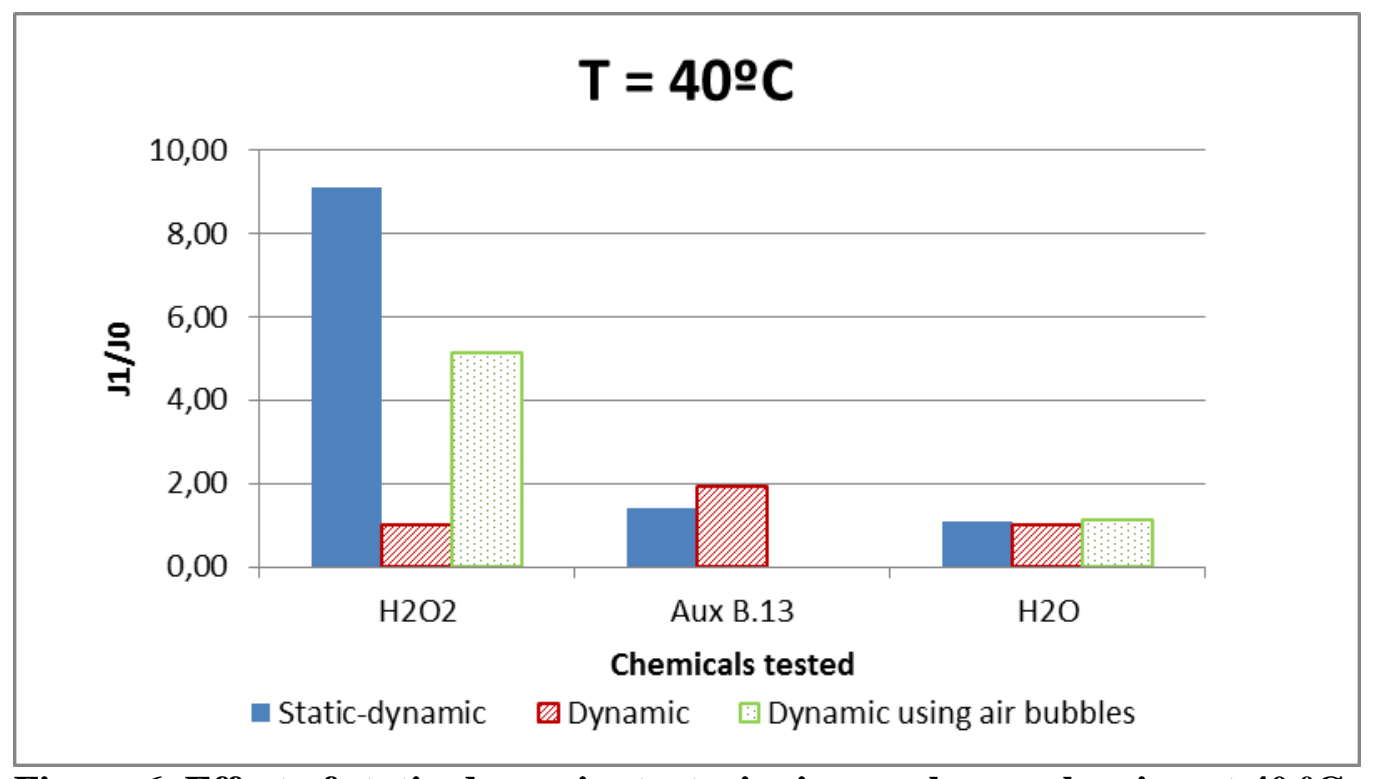

Figure 6. Effect of static-dynamic strategies in membrane cleaning at $40{ }^{\circ} \mathrm{C}$

\subsection{Combination of diferent solutions}

Due to cleaning sequence application is known to affect the degree of permeability recovery [34], different cleaning sequences were tested for the solutions that performed the best results in the degree of flux recovery with a single reagent. Duration of the test was increased to the double, just to assure that both solutions remain the same time in contact with the fouled membrane. Solutions selected were hydrogen peroxide and sodium hypochlorite. The degree of flux recovery reached for this solutions were the highest values (12.9 and 10.8 respectively).

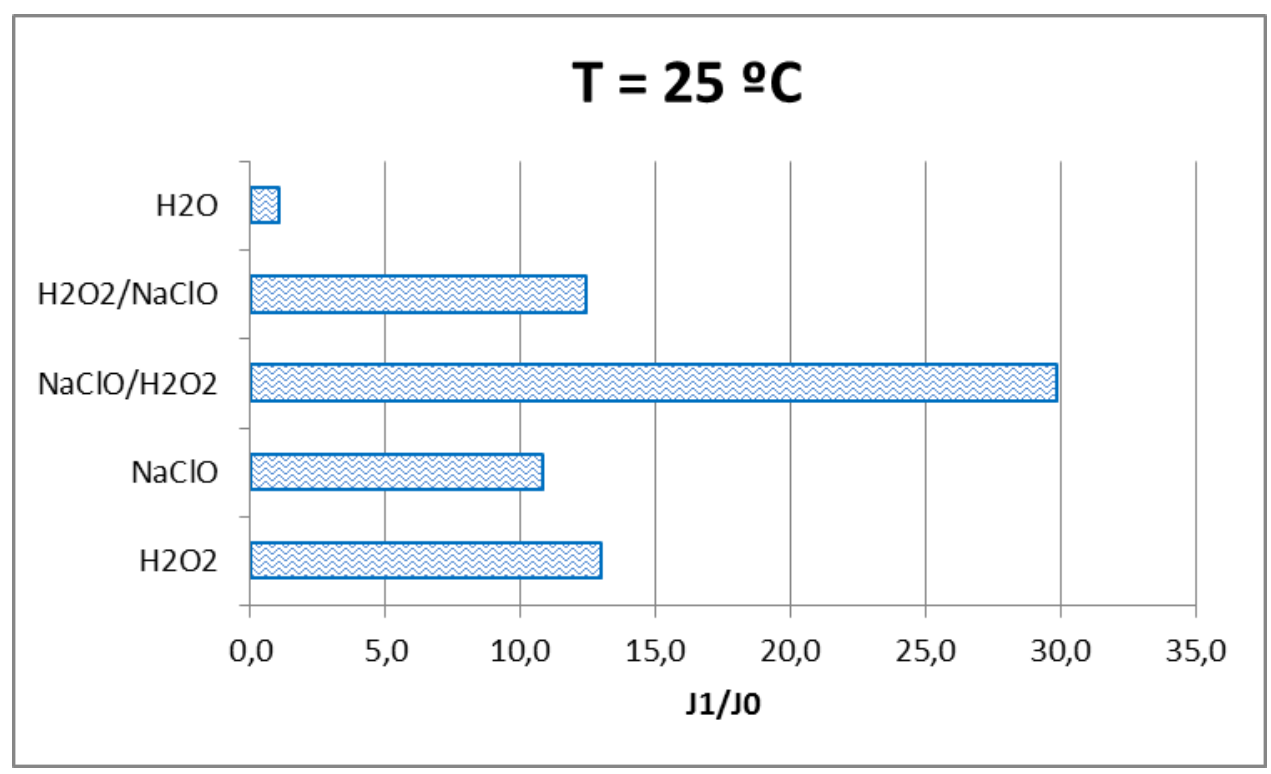

Figure 7. Effect of cleaning agent sequence

As it can be seen in Figure 7, for the sequence of sodium hypochlorite-hydrogen peroxide, the total degree of flux restoration (29.9) seems to have an additive effect compared with the single reagents (10.8 and 12.9 respectively).

However, the opposite sequence hydrogen peroxide followed by sodium hypochlorite does not show any significant effect. The degree of flux restoration for this sequence remains equal to the one obtained for the single reagent (in this case Hydrogen peroxide). 
Therefore, it seems that the oxidative properties of hypochlorite may be more significant than the hydrolysis catalysing effect of the peroxide [35] when used in a combined sequence. This could be explained due to a better removal of organics through oxidation of aromatic humic susbtances at elevated $\mathrm{pH}$ levels [35] as a consequence of the action of the sodium hypochlorite, followed by the oxidation effect of the hydrogen peroxide. This effect, not observed before for the combination of these two oxidants by previous authors, has been reported for alkaline and oxidant agents sequence, specially where organics foulants dominate [35-38]. In our case, the sodium hypochlorite provides alkaline and oxidation effect while hydrogen peroxide strengthens the oxidant effect. This effect is also improved by the static-dynamic hydrodynamic effect that helps the diffusion of the cleaning reagents from the membrane surface [39].

\section{Conclusions}

The static-dynamic cleaning strategy improves the results of cleaning obtained for dynamic and air bubbles dynamic test.

Soaking time combined with the hydrodynamic effect promoted by the recirculation of the cleaning reagent helps the diffusion of the chemicals on the membrane surface.

The use of oxidants as Sodium Hypochlorite and Hydrogen Peroxide removes effectively the drinking water foulants of UF membranes.

The combined sequence Sodium Hypochlorite and Hydrogen Peroxide, helps to oxidate and degrade NOM due to the oxidant and hydrolytic effect of the Sodium Hypochlorite and its high $\mathrm{pH}$. Opposite sequence did not improved the results obtained for Hydrogen Peroxide alone.

\section{References}

[1] J.M. Laine, D. Vial and P. Moulart. Status after 10 years of operation-overview of UF technology today. Desalination 131 (2000) 17-25.

[2] A. Rahimpour, S. S. Madaeni and Y. Mansourpanah. High performance polyethersulfone UF membrane for manufacturing spiral wound module: preparation, morphology, performance, and chemical cleaning. Polym. Adv. Technol. 18 (2007) 403-410.

[3] E.R. Cornelissen, J.S. Vrouwenvelder, S.G.J. Heijman, X.D. Viallefont, D. Van Der Kooij, L.P. Wessels. Periodic air/water cleaning for control of biofouling in spiral wound membrane elements. Journal of Membrane Science 287 (2007) 94-101.

[4] M.F.A Goosen, S.S. Sablani, H. Al-Hinai, S. Al-Obeidani, R. Al-Belushi, D. Jackson. Fouling of reverse osmosis and ultrafiltration membranes: a critical review. Separation Science and Technology 39 (2004) 2261-2297.

[5] E. Aoustin, A.I. Schäfer, A.G. Fane, T.D. Waite. Ultrafiltration of natural organic matter. Separation and Purification Technology 22-23 (2001) 63-78.

[6] P. Bacchin, P. Aimar, V. Sanchez. Model for colloidal fouling of membranes. AIChE Journal 41 (1995) 368-376.

[7] T. Carroll, S. King, S.R. Gray, B.A. Bolto, N.A. Booker. The fouling of microfiltration membranes by NOM after coagulation treatment. Water Research 34 (2000) 2861-2868.

[8] N. Porcelli, S. Judd. Chemical cleaning of potable water membranes: A review. Separation and Purification Technology 71 (2010) 137-143.

[9] S. Ebrahim, H.E. Dessouky. Evaluation of chemical cleaning agents for sea water reverse osmosis membranes. Desalination 99 (1994) 169-173. 
[10] S. Ebrahim. Cleaning and regeneration of membranes in desalination and wastewater applications: state-of-the-art. Desalination 96 (1994) 225-238.

[11] A. Al-Amoudi, W.L. Lovitt. Fouling strategies and the cleaning system of NF membranes and factors affecting cleaning efficiency. Journal of Membrane Science 303 (2007) 4-28.

[12] D. Chen, L.K. Weavers, H.W. Walker. Ultrasonic control of ceramic membrane fouling: effect of particle characteristics. Water Research, 40 (2006) 840-850.

[13] R.S. Juang, K.H. Lin. Flux recovery in the ultrafiltration of suspended solutions with ultrasound. Journal of Membrane Science, 243 (2004) 115-124.

[14] A. Saxena, B.P. Tripathi, M. Kumar, V.K. Shahi. Membrane-based techniques for the separation and purification of proteins: An overview. Advances in Colloid and Interface Science 145 (2009) 1-22.

[15] C.C. Tarazaga; M.E. Campderros, A.P. Padilla. Physical cleaning by means of electric field in the ultrafiltration of a biological solution. Journal of Membrane Science 278 (2006) 219-224.

[16] C.V. Vedavyasan. Potential use of magnetic field a perspective. Desalination 134, (2001), 105-108.

[17] J.S. Baker, S.J. Judd. Magnetic amelioration of scale formation. Water Research 30 (1996) 247-260.

[18] H. Liang, W. Gongb, J. Chen, G. Li. Cleaning of fouled ultrafiltration (UF) membrane by algae during reservoir water treatment. Desalination 220 (2008) 267-272.

[19]. J.P. Chen, S.L. Kim, Y.P. Ting. Optimization of membrane physical and chemical cleaning by a statistically designed approach. Journal of Membrane Science 219 (2003) 27-45.

[20]. S.S. Madaeni, Y. Mansourpanah. Chemical cleaning of reverse osmosis membranes fouled by whey. Desalination 101 (2004) 13-24.

[21] G. Tragardh. Membrane cleaning. Desalination 71 (1989) 325-335.

[22] R. Liikanen, J. Yli-Kuivila, R. Laukkanen. Efficiency of various chemical cleanings for nanofiltration membrane fouled by conventionally-treated surface water. J. Membrane Sci. 195 (2002) 265-276.

[23] M. Bartlett, M.R. Bird, J.A. Howell. An experimental study for the development of a qualitative membrane cleaning model. Journal of Membrane Science 105 (1995) 147-157.

[24] J.M. Arnal, B. Garcia-Fayos, M. Sancho, G. Verdu. Cleaning ultrafiltration membranes by different chemical solutions with air bubbles. Desalination and water Treatment, 10 (2009)198-205.

[25] J.Q.J.C. Verberk, P.E. Hogeveen, H. Futselaar, J.C. van Dijk. Hydraulic distribution of water and air over a membrane module using AirFlush ${ }^{\circledR}$. Water, Science and Technology: Water Supply 2(2002) $297-$ 304.

[26] C. Guigui, M. Mougenot, C. Cabassud. Air sparging backwash in ultrafiltration hollow fibres for drinking water production. Water, Science and Technology: Water Supply 3(2003) 415-422.

[27] M. Peter-Varbanets, C. Zurbrugg, C. Swartz, W. Pronk. Decentralized systems for potable water and the potentialof membrane technology. Water research 43 (2009) 245-265.

[28] R. Butler. SkyJuice Technology impact on the UN MDG outcomes for safe affordable potable water. Proceedings of International Workshop Water and Sanitation in International Development and Disaster Relief, Edinburg UK (2008)

[29] J.M. Arnal, M. Sancho, G. Verdú, J. Lora, J.F. Marin, J. Chafer Selection of the most suitable ultrafiltration membrane for water disinfection in developing countries Desalination 168 (2004) 265-270

[30] J.M. Arnal, M. Sancho, B. García-Fayos, J. Lora, G. Verdú. Aquapot: UF real applications for water potabilization in developing countries. Problems, location and solutions adopted, Desalination 204 (2007) 316-321.

[31] J.M. Arnal, B. García-Fayos, G. Verdú, J. Lora, M. Sancho. Aquapot: Study of the causes in reduction of permeate flow in spiral wound UF membrane. Simulation of a non-rigorous cleaning protocol in a drinkable water treatment facility, Desalination 222 (2008) 513-518

[32] J.M. Arnal, B. Garcia-Fayos, M. Sancho, G. Verdu. Ultrafiltration membrane cleaning with different chemical solutions after treating surface water, Desalination and Water Treatment 7 (2009) 198-205

[33] J.M. Arnal, B. García-Fayos, J. Lora, G. Verdu, M. Sancho. Aquapot: Study of several cleaning solutions to recover permeate flow in a humanitarian drinking water treatment facility based on spiral wound UF membrane. Preliminary test (I). Desalination 221 (2008) 331-337.

[34] L.J. Zeman, A.L. Zydney, Microfiltration and Ultrafiltration: Principles and Applications,1st ed., Marcel Dekker Inc., New York, 1996.

[35] S. Strugholtz, K. Sundaramoorthy, S. Panglisch, A. Lerch, A. Brugger, R. Gimbel, Evaluation of the performance of different chemicals for cleaning capillary membranes. Desalination 179 (2005) 191-202

[36] S. Hong, M. Elimelech, Chemical and physical aspects of natural organic matter (NOM) fouling of nanofiltration membranes. Journal of Membrane Science 132 (1997) 159-181.

[37] C.-F. Lin, S.-H. Liu, O.J. Hao. Effect of functional groups of humic substances on UF performance, Water Research 35 (2001) 2395-2402. 
[38] E. Zondervan, B. Roffel, Evaluation of different cleaning agents used for cleaning ultrafiltration membranes fouled by surface water, Journal of Membrane Science 304 (2007) 40-49

[39] H. Huang, N. Lee, T. Young, A. Gary, J.C. Lozier, J.G. Jacangelo, Natural organic matter fouling of low-pressure, hollow-fibre membranes: effects of nom source and hydrodynamic conditions, Water Res. 41 (2007) 3823-3832. 